\title{
An Analysis of the Stacking Potential and Efficiency of Plant- Microbial Fuel Cells Growing Green Beans (Vigna ungiculata ssp. sesquipedalis)
}

\author{
Kristopher Ray S. Pamintuanª,b*, Angelika Michelle C. Katipunana, Patricia Ann O. \\ Palaganas $^{a}$, Alvin R. Caparanga ${ }^{a}$
}

${ }^{a}$ School of Chemical, Biological, and Materials Engineering and Sciences, Mapua University, Manila, Philippines

${ }^{b}$ Center for Renewable Bioenergy Research, Mapua University, Manila, Philippines

\begin{abstract}
Plant-Microbial Fuel Cell (PMFC) technology is a promising bioelectrochemical system that can exploit natural plant rhizodeposition to generate electricity. PMFCs can be used to simultaneously generate electricity while growing edible plants, as illustrated in this study. However, the common problem encountered for soil PMFCs is the low power output. To solve this problem, the stacking behavior of PMFCs was examined to maximize the power output of several cells. A grid of 9 PMFCs (3x3) was constructed with stainless steel and carbon fiber electrodes growing green beans (V. ungiculata spp. sesquipedalis) for stacking purposes. Stacking results have shown that too many cells connected in series will result in voltage losses, while stacking in parallel conserves voltage between cells. Stacking a maximum of 3 cells in series is acceptable based on the results, since cumulative stacking revealed that voltage reversals can reduce the overall potential of the stack if there are too many connected cells. Stack combinations were also tested, resulting in an enhanced performance upon combining series and parallel connections allowing power to be amplified and power density to be conserved. The combination of three sets of three cells in series stacked in parallel (3S-P) generated the highest power and power density (160.86 $\left.\mu \mathrm{W} / \mathrm{m}^{2}\right)$ amongst all combinations, showing that power amplification without losses to power density are possible in PMFC stacking. Overall, proper stacking combinations have been shown to greatly affect the performance of PMFCs. It is hoped that the results of this study will contribute to the efforts of applying PMFC technology on a larger scale. C2020. CBIORE-IJRED. All rights reserved
\end{abstract}

Keywords: stacking efficiency, renewable energy, bioelectrochemical systems, Plant-Microbial Fuel Cells, solar bioenergy

Article History: Received: $4^{\text {th }}$ May 2020; Revised: $4^{\text {th }}$ July 2020; Accepted: $19^{\text {th }}$ July 2020; Available online: $3^{\text {rd }}$ August 2020

How to Cite This Article: Pamintuan, K.R.S.., Katipunan, A.M.C., Palaganas, P.A.O., Caparanga, A.R. (2020) An Analysis of the Stacking Potential and Efficiency of Plant-Microbial Fuel Cells Growing Green Beans (Vigna ungiculata ssp. sesquipedalis). International Journal of Renewable Energy Development, 9(3), 439-447

https://doi.org/10.14710/ijred.2020.29898

\section{Introduction}

An increasing pressure to reduce our carbon emissions from the energy sector to curb excessive global warming points to the development of renewable energy technologies. Bioelectrochemical systems (BES) as applied to renewable energy generation shows promise as it utilizes living systems to generate electricity or produce energy-dense compounds (Bajracharya et al., 2016). One subclass of BESs are Plant-Microbial Fuel Cells (PMFCs). They serve the same functions as solar photovoltaic cells; PMFCs generate electricity from sunlight that drives photosynthesis, forming carbon compounds. Some of these compounds are stored by the plant while some are excreted through the roots through a process called rhizodeposition (Nitisoravut \& Regmi, 2017; Bais et al 2006). The rhizodeposits, mainly composed of simple sugars and amino acids (Bacilio-Jiménez et al., 2003), are consumed by bacteria in the rhizosphere. Some bacteria, called exoelectrogenic bacteria, are capable of releasing protons and electrons from their cells through extracellular electron transfer (Ishii et al., 2017). Through this process, PMFCs generate electricity by utilizing sunlight to fix atmospheric carbon to its roots, which in turn is oxidized by rhizospheric bacteria. This makes PMFCs a carbon-neutral electricity generator. PMFCs are also attractive to use in agricultural lands as it permits the simultaneous generation of electricity and biomass production.

Before PMFCs can be applied on a large scale for green electricity generation, design characteristics and other process variables are to be optimized to reduce cost and maximize power. Attempts to optimize fuel cell elements such as electrode material, spacing, configurations, model plant, substrate, and in-situ applications are well documented for Microbial Fuel Cells (MFCs) (Pamintuan, Bagumba, \& Domingo, 2020)(Zhou et al., 2017)(Hou, Liu, \& Li, 2015)(Logan et al., 2006), but not for PMFCs. The key difference is that PMFCs are mainly applied in plantsustaining soil while MFCs are operated in aqueous

* Corresponding author: krspamintuan@mapua.edu.ph 
solutions and are often fed with wastewater. Literature is scarce for PMFCs using food-bearing plants, with Oryza sativa (paddy rice) as an exemption. In an actual field study of PMFCs growing $O$. sativa, it was reported that power densities were about $75 \%$ higher if the cathodic surface area is larger than the anode, indicating that the cathodic reaction is rate-limiting in established PMFCs (Ueoka, Sese, Sue, Kouzuma, \& Watanabe, 2016). Another study investigated the use of maple wood biochar as anode material on the power generation and methane production of paddy soil with $O$. sativa. While power generation was about $73 \%$ lower than a PMFC using carbon felt as anode, methane emissions were about 39\% lower for those with biochar anodes (Khudzari, Gariepy, Kurian, Tartakovsky, \& Raghavan, 2018). If PMFCs are to be applied in farmlands, more studies are to be conducted with foodbearing plants and improved designs and configurations.

The stacking of PMFCs was previously reported for aquatic cells growing Ipomoea aquatica (water spinach) and Pistia stratiotes (water lettuce)( Pamintuan, Clomera, Garcia, Ravara, \& Salamat, 2018) with promising results. It was demonstrated that aquatic PMFCs have additive voltage and constant current in series connection, and additive current and constant voltage in parallel connection, a behavior similar to commercially available electrochemical cells. This information is important for scaling-up as smaller stacked cells are more efficient than one large cell, at least in MFCs (Greenman \& Ieropoulos, 2017). Stacking cells in various configurations have been shown to reduce internal resistance and increase power density in MFCs (Ieropoulos et al 2013)(Yazdi et al 2015). Although stacking behavior was positive with aquatic PMFCs, the same is yet to be demonstrated to terrestrial PMFCs. As this is the first study that tackles stacking in terrestrial PMFCs, elucidating the stacking behavior of soil PMFCs will hopefully lead to increased performance and the possibility of in-field large-scale application.

This study aims to characterize the stacking capability of low-cost terrestrial PMFCs growing Vigna ungiculata spp. sesquipedalis (green bean), a commonly grown foodbearing plant. Stacking limits, mixed stack configurations, and voltage losses will be discussed and its implications in scale-up will be examined. This study is the first of its kind as it uses a fruit-bearing legume ( $V$. ungiculata) to illustrate the possibility of concurrent food and electricity generation in the same land. This bears great importance as developments could lead to farmlands being capable of generating appreciable amounts of green electricity while continuing to provide food for the people. Doing so could lead to further innovations in design for terrestrial stacked PMFCs, with the ultimate goal of bringing the technology on the field for simultaneous electricity generation and biomass production.

\section{Materials and Methods}

\subsection{PMFC Configuration}

The PMFC set-up was constructed using twin-wall polycarbonate plastic with the same dimensions as reported previously (Pamintuan et al., 2018). The design is shown in Figure 1. The specific design was chosen to incorporate a biocompatible anode (carbon felt, Sinotek Materials Co., Ltd., China) and a catalyzing cathode (stainless steel 304, Anping ADY, China). Both electrodes have a nominal dimension of $10.16 \mathrm{~cm}$ by $2.54 \mathrm{~cm}(25.8$ $\mathrm{cm}^{2}$ ). Holes were drilled in the bottom of the container to facilitate the draining of excess water and oxygenation of the soil near the cathode. Loam garden soil was sourced from a gardening shop and was first thoroughly mixed in bulk before placing in PMFCs to ensure a consistent composition of the soil. A piece of cotton cloth with the same dimensions as the cross-section of the PMFC (232.26 $\mathrm{cm}^{2}$ ) was placed between the anode and cathode to act as a low-cost separator. An external resistor (2000 $\Omega, 0.25 \mathrm{~W})$ was connected to each anode-cathode pair of the PMFCs to close the circuit. The resistance value was chosen considering that an external resistance higher than the internal resistance of the cell would most likely lead to larger losses compared to a lower resistance value (Nikhil, Krishna Chaitanya, Srikanth, Swamy, \& Venkata Mohan, 2018). From a previous study on terrestrial PMFCs, internal resistances were measured to be around 800010000 ohms (Kristopher Ray S. Pamintuan \& Sanchez, 2019).

Fifty (50) seeds of $V$. ungiculata were grown for 20 days in seed trays with moist loam soil. After germination, they were transplanted to the constructed PMFC assemblies, making sure that the roots will touch the anode. $V$. ungiculata was chosen as a model plant for several reasons: it hosts nitrogen-fixing bacteria in the roots which can be important in PMFC operations (Nitisoravut \& Regmi, 2017), it is a commonly grown crop in tropical countries, and it can be harvested multiple times, thereby lengthening the time that the plant spends in the soil which is beneficial for PMFCs. This allows for continuous harvest of biomass and bioelectricity from the plants. Transplanting was done early in the morning to avoid temperature shock to the plants. Nine plants were selected to be transplanted based on similarities in initial height $(21.62 \mathrm{~cm} \pm 1.82 \mathrm{~cm})$, number of leaves $(>6)$, and vigor. The soil was not compressed. All cells were watered twice daily, morning and afternoon, with $50 \mathrm{~mL}$ of distilled water per cell per watering. No fertilizers were used for the plants.

\subsection{Stacking potential and efficiency}

Voltage was the primary parameter measured against a 2000- $\Omega$ external resistor using a multimeter (RS Pro RS12). Current $(I=V / R)$, current density $\left(I_{d}=I / A\right)$, power $\left(P=V^{2} / R\right)$, and power density $\left(P_{d}=P / A\right)$ where A is the nominal anode area were then computed from voltage data. Voltage was measured daily for individual cells (IND), 3 cells stacked in series (3S), 3 cells stacked in parallel (3P), 9 cells stacked in series (9S), and 9 cells stacked in parallel (9P). Several possible non-repeating permutations for stacking were performed to have a clear picture of the stacking characteristics of PMFCs. Furthermore, series and parallel combination stacks were also observed: 3 sets of 3 cells in series stacked in parallel (3S-P), and 3 sets of 3 cells in parallel stacked in series (3P-S). To determine stacking efficiency, cumulative stacking tests were performed. In these tests, an increasing number of cells were sequentially stacked in series and parallel (e.g. 1, then 1-2, then 1-2-3, and so on) to determine the behavior of voltage as the stack size increases. This allows for the determination of the maximum number of cells that can be efficiently stacked as well as the potential drop for stacking too many cells. 
(a)

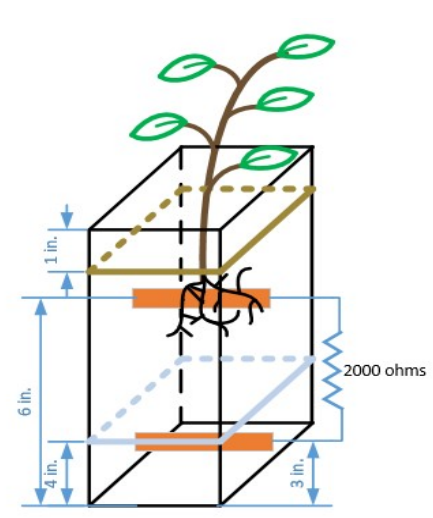

(b)

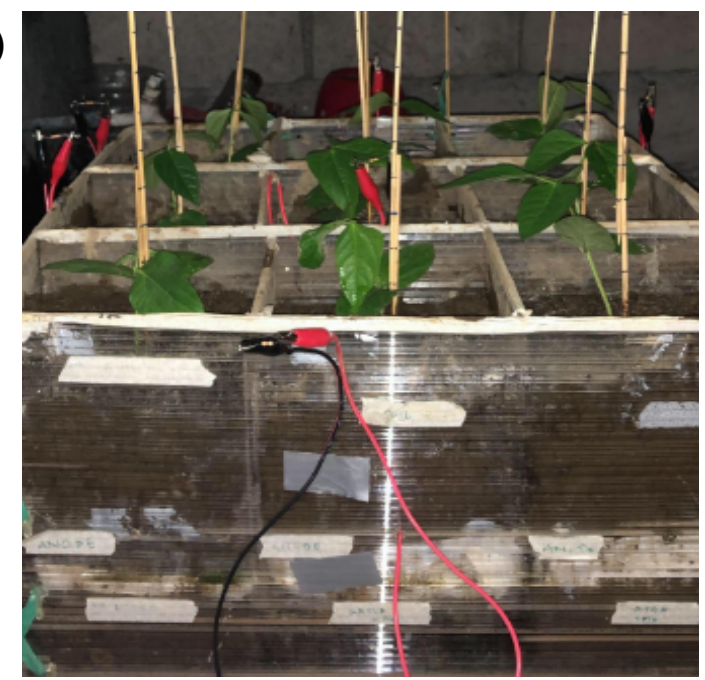

Fig 1. Designed PMFC Assembly: (a) individual cell; (b) group of 9 cells for convenient stacking

\subsection{Measurement of possible heavy metal contamination}

Since the PMFCs in this study are valued for both bioelectricity generation and biomass (food) production, the amounts of chromium and nickel must be determined from the system. This is part of the hypothesis that one of the drawbacks of using stainless steel as the cathode material is the possibility of it leaching chromium and nickel to the soil, and worse, to the plant. To ensure the safety of stainless steel in PMFCs, the amounts of nickel and chromium were determined from the soil, leaves, and bean pod samples after the experiment. The concentrations of the heavy metals were determined both for pristine samples (control, no electrodes were placed) and for the samples inside the PMFC.

The samples were first oven-dried at $80^{\circ} \mathrm{C}$ in an oven until constant weight. The samples were then pulverized using a blender and digested in sufficient amounts of $70 \%$ nitric acid under gentle heating until brown fumes cease to form (around 30 minutes) (Pequerul, Perez, Madero, Val, \& Monge, 1993). The resulting solutions were filtered and diluted to $50 \mathrm{~mL}$. The solutions were processed in Inductively Coupled Plasma - Optical emission Spectroscopy (ICP-OES, Perkin Elmer Optima 8000) for determination of chromium and nickel content using standard calibration method. The operation of the instrument was followed from the application note provided (Sarojam, 2010).

\section{Results}

\subsection{Individual performance of PMFCs}

The PMFCs were monitored for a minimum of 50 days after transplanting with combined vegetative and reproductive stages. This allows for the observation of the voltage of PMFCs concerning the growth stage of the plant. The growth of plants is generally differentiated into two main stages: the vegetative stage and reproductive stage. The two stages are differentiated by the presence of carbon sinks in the plant. During the vegetative stage, the roots are carbon sinks, while seeds and fruits are carbon sinks during the reproductive stage (Holland, Monk, Clayton, \& Osborne, 2019). The voltage trend of the individual cells is shown in Figure 2. The observed onset of flowers started at day 18. A steady increase in voltage was observed during the vegetative stage as more rhizodeposits are exuded in the roots, then the voltage of PMFCs started to decrease at the onset of flowering (day 18), and further decreased during fruit development. This pattern was consistent with findings on different varieties of rice (Oryza sativa), noting that in general, rhizodeposition decreased during the fruiting stage (Aulakh, Wassmann, Bueno, Kreuzwieser, \& Rennenberg, 2001). This suggests an increase of nutrition priority to the fruits of the plant decreases the rhizodeposits available for microorganisms in the rhizosphere, leading to lower bioelectrical output. This is another hurdle for PMFCs growing food plants as most of them are valued for their fruits. However, there are also indications that the translocation of carbon compounds to the roots is enhanced upon removal of carbon sinks in the plant, i.e., removal of the fruits(Kläring, Hauschild, \& Heißner, 2014). Hence, such fluctuations in voltage of PMFCs growing food plants are expected and mainly attributed to its development stage and presence of carbon sinks.

There is a considerable variation in the voltage output of the individual cells. On average, voltages of the cells varied by about $115 \%$ from the daily mean. Such a large variation in voltage output is attributed to several factors such as plant physiology, microbial population of the rhizosphere, soil condition, environmental effects, and other factors that are difficult to control (Nitisoravut \& Regmi, 2017). This also shows that variation in power output is evident even in similarly constructed cells, a factor that will be important when considering large-scale applications.

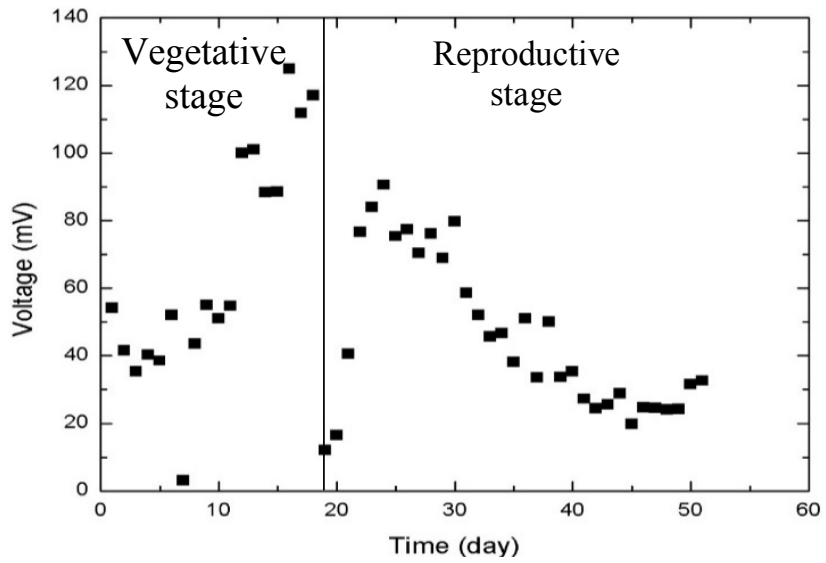

Fig 2. Average individual voltages of PMFCs showing the divide between vegetative and reproductive stages 


\subsection{Pure Series and Parallel Stacks}

The daily average voltage of individual (IND), 3 cells stacked in series (3S), and 3 cells stacked in parallel (3P) are shown in Figure 3. The trends of the three curves are noticeably similar, with the individual and 3 cells stacked in parallel overlapped with each other. This confirms what we already know for batteries; three cells connected in parallel would exhibit the same voltage of a single cell, similar to previous reports on open-circuit aquatic PMFCs (K.R.S. Pamintuan et al., 2018). However, for series connection, it is expected that the voltage of three cells connected in series would be 3 times that of the individual voltage. The data suggests that on average, it is only about 2.4 times the individual voltage.

This discrepancy was further examined by repeatedly measuring both voltage and current of different permutations of cells connected in series and parallel during the latter stages of the experiment where the voltage has stabilized. In Figure 4a, the actual voltage of 3 cells in series is on par with the expected or theoretical voltage.

However, this is only true because of the large variation in samples resulting in a high standard deviation. If the observations are interpreted individually, about $75 \%$ of samples in series showed voltages that are $75 \%$ lower than that of the theoretical. This difference in voltages can be attributed to losses due to connections and it is expected to be magnified as more cells are connected. The actual current of the cells connected in series is in agreement with the theoretical, which should be the same current of the individual cell.

For three cells connected in parallel (Figure 4b), it is expected that the current of the stacked cells is three times the current of the individual cell and the voltage of the stack will be similar to the voltage of the individual cells. In terms of voltage, the expectations were met, even overshot. However, for the current of the cells connected in parallel, there is a large discrepancy in actual and expected values. Further analysis of the data revealed that the current exhibited by a stack of three parallel cells is only equivalent to the current of an individual cell. Thus, parallel stacking can preserve the voltage of the group at the expense of lower current. By now, the problem with stacking bioelectrical systems is unfolding; when polarized, they do not behave in the same way as batteries.

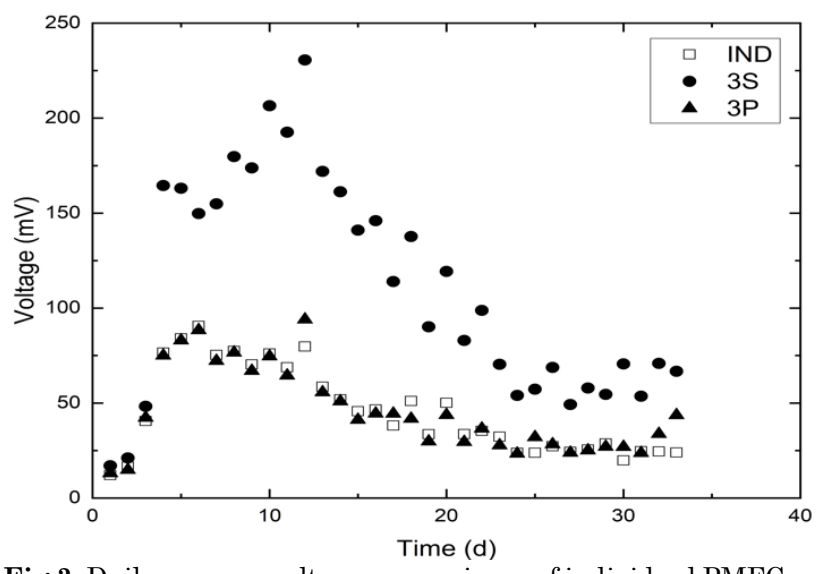

Fig 3. Daily average voltage comparisons of individual PMFCs to those stacked in series and parallel
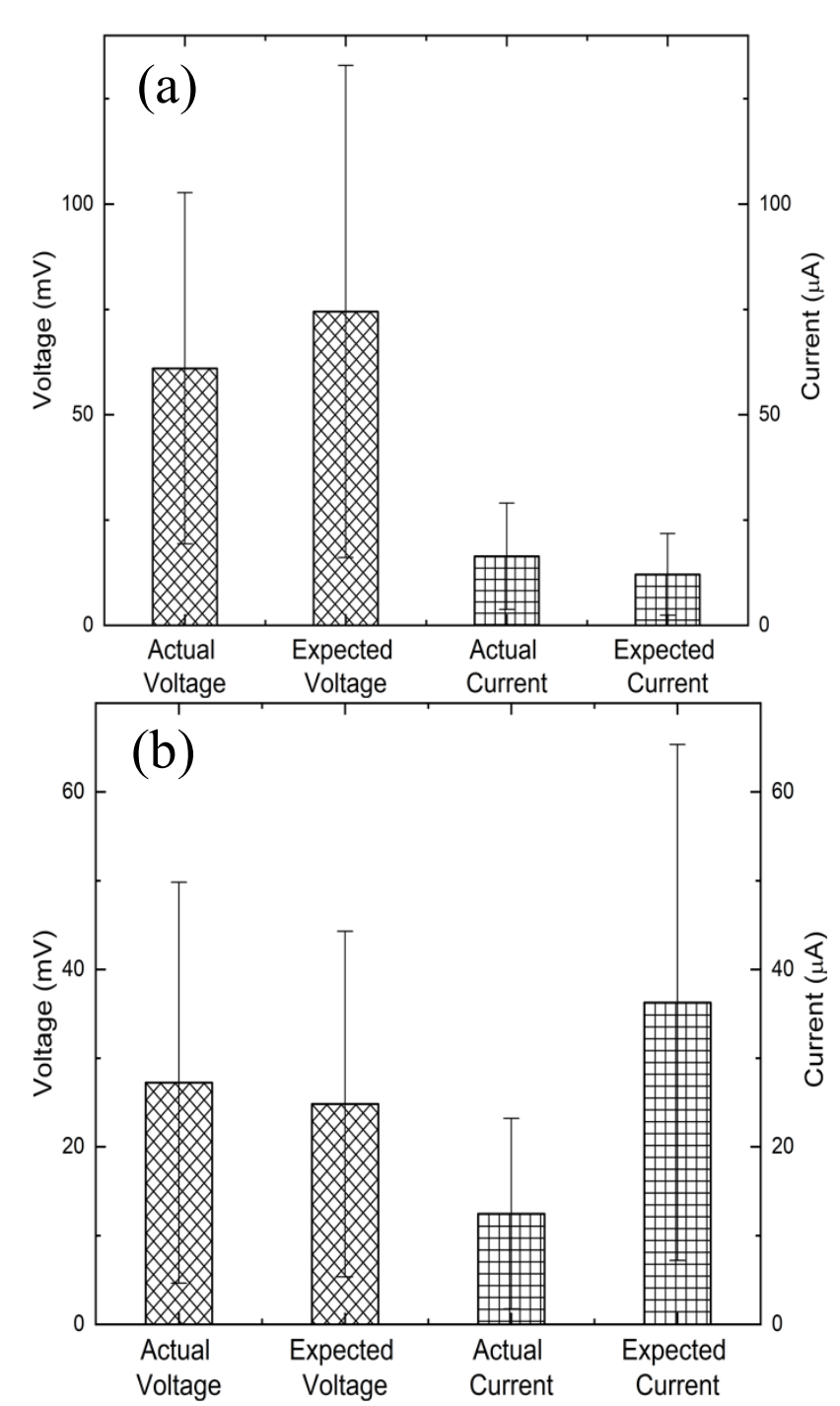

Fig 4. Averaged voltage and current of 3 cells connected in (a) series and (b) parallel compared to the expected values

Stacks of 9 cells in series and parallel were also investigated, and the results are summarized in Figure 5. The results were similar to the previous stacks of 3 cells, but the problems are more evident; large voltage drop for series connection (only $38 \%$ of theoretical), and large current drop for parallel connection (only 13\% of theoretical). The losses previously noted in stacking 3 cells were much more magnified, suggesting that the losses are a function of the number of cells connected (Oh \& Logan, 2007). As such, the results prompted the addition of cumulative stacking to the analysis.

\subsection{Cumulative Stacking}

Cumulative stacking was performed to determine the progression of losses in the stacking chain. It can help identify faulty cells or identify the most efficient number of cells that can be stacked. Shown in Figure 6 are the results of cumulative series and parallel stacking. 


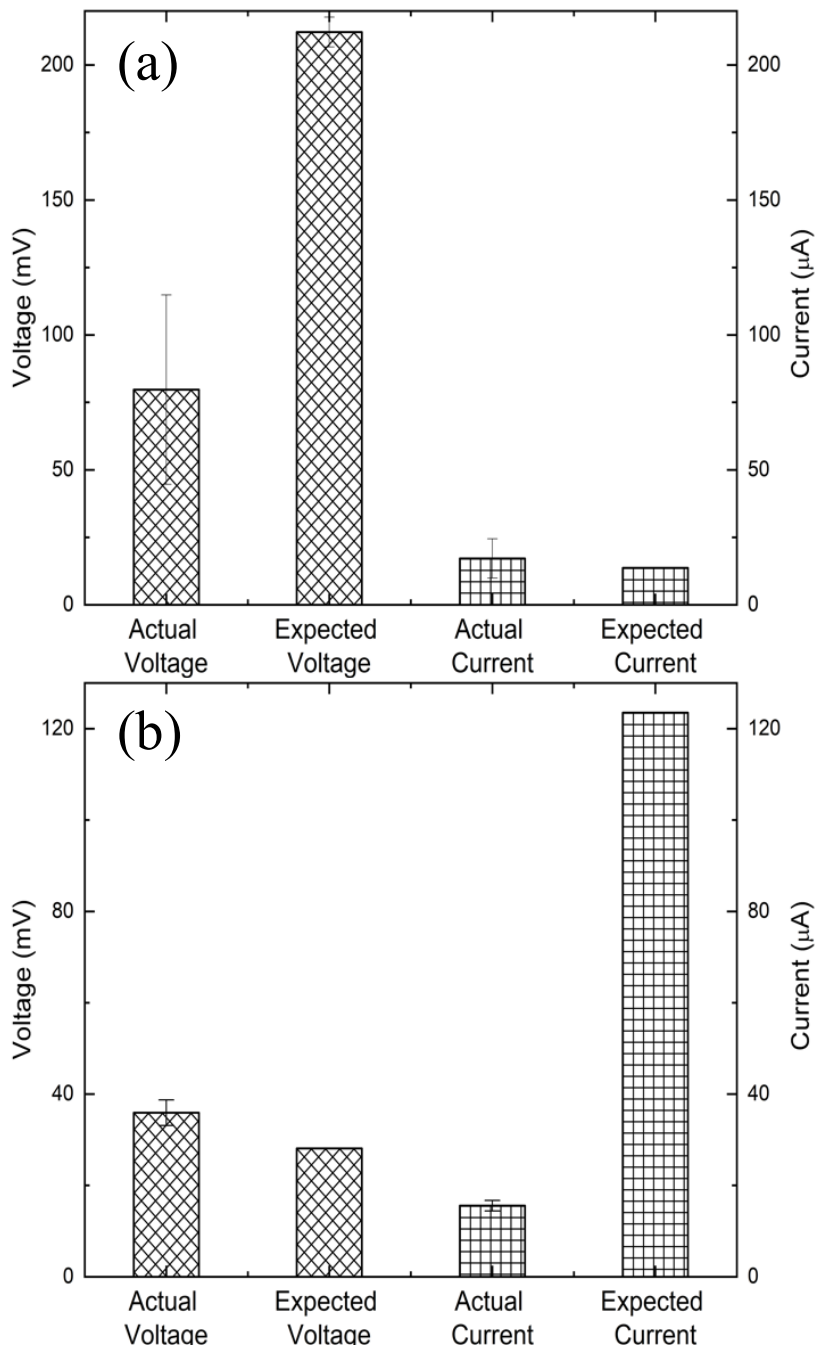

Fig 5. Averaged voltage and current of 9 cells connected in (a) series and (b) parallel compared to the expected values

The cumulative stacking verified the results from stacking 9 cells in series and parallel. There is an appreciable amount of voltage loss for series stacking beyond 3 cells (Figure 6a) in which the voltage failed to increase even as more cells are connected. This reveals the electrical nature of PMFCs as flawed generators of electricity. The failure of one cell across a string of many stacked cells will result in a lower total voltage of the system (Estrada-Arriaga et al., 2017). However, the data shows that faulty cells are not the problem, as pictured by the rising theoretical line. Thus, the problem of the stack is voltage reversal. In Microbial Fuel Cell (MFC) studies, voltage reversals were observed to occur under a variety of circumstances such as the presence of a weak cell causing the stronger cells to "charge" the weak cell or the variation of internal impedance due to membrane separator fouling (Gurung \& Oh, 2012). When voltage reversal occurs, the polarity of the weak cell switches, making the anode positive and the cathode negative. In a series connection, this results in a voltage decrease rather than an increase due to the negative potential of the weak cell. Cumulative stacking in parallel (Figure 6b) showed higher stack voltages than expected. In a parallel connection, the voltage of the stack is expected to be the average voltage of the cells.
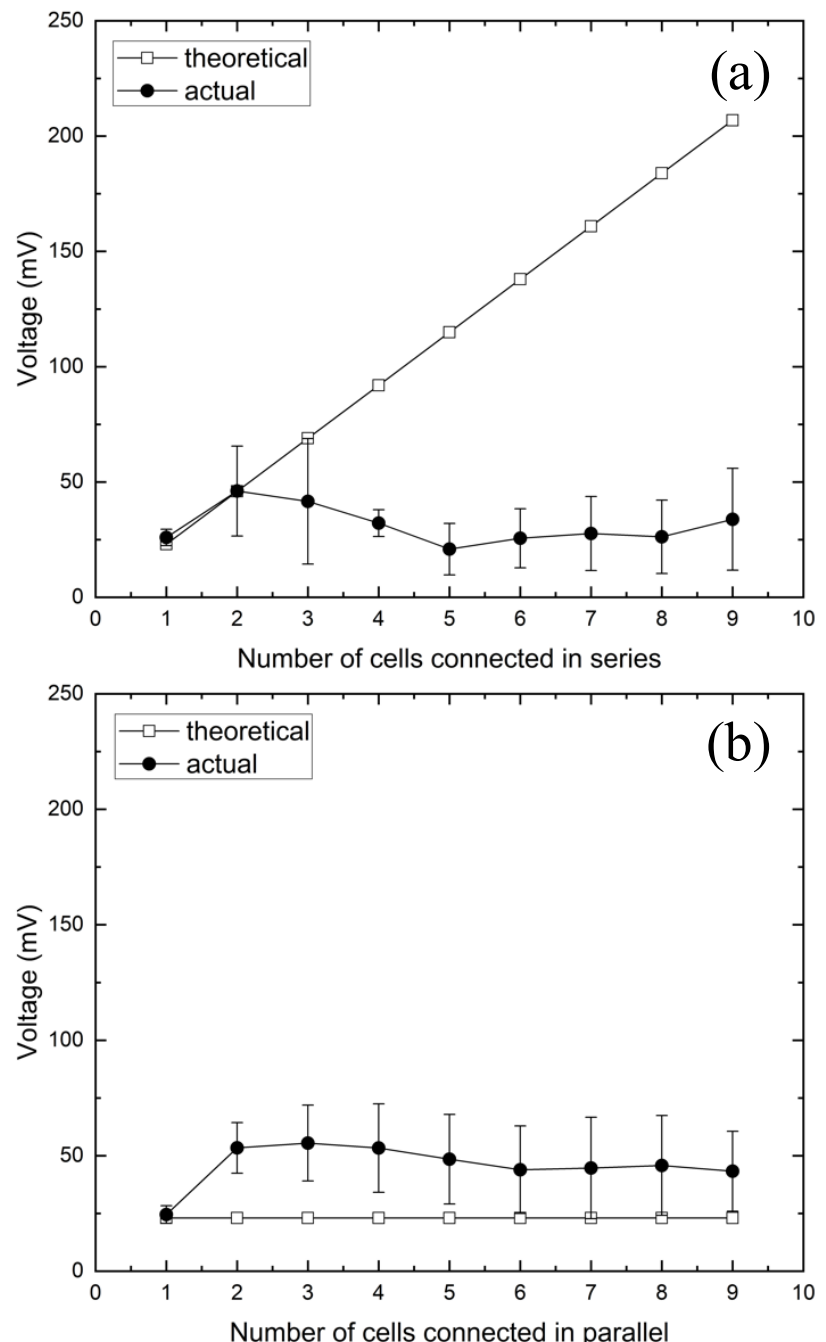

Fig 6. Response of voltage to cumulative stacking in (a) series and (b) parallel

A higher stack voltage in parallel was observed for all trials and permutations. These results are consistent with stacking 3 and 9 cells in parallel. The results suggest that parallel stacking prevents losses in voltage but is consistently generating lesser current than expected. Furthermore, too many cells connected in series are preserving the current but fail to reach higher voltage, leading to problems in large-scale systems. Thus, stack combinations are also tested to see if it solves this problem.

\subsection{Stacking Combinations}

Tests on stacking combinations were performed beyond day 30 as the average voltage of the individual cells were reaching a stable value. Two configurations were observed: 3 sets of 3 cells in series stacked in parallel (3S$\mathrm{P}$ ) and 3 sets of 3 cells in parallel stacked in series (3P-S). The idea was to cancel out both the strengths and weaknesses of series (failure of voltage increase beyond 3 cells but can sustain current) and parallel connections (consistently high stack voltages but cannot increase current). The results are summarized in Figure 7. 
Citation: Pamintuan, K.R.S., Katipunan, A.M.C., Palaganas, P.A.O., Caparanga, A.R. (2020) An Analysis of the Stacking Potential and Efficiency of Plant-Microbial Fuel Cells Growing Green Beans (Vigna ungiculata ssp. Sesquipedalis). Int. Journal of Renewable Energy Development, 9(3), 439-447, doi: 10.14710/ijred.2020.29898

$\mathrm{P}$ a g e $\mid 444$

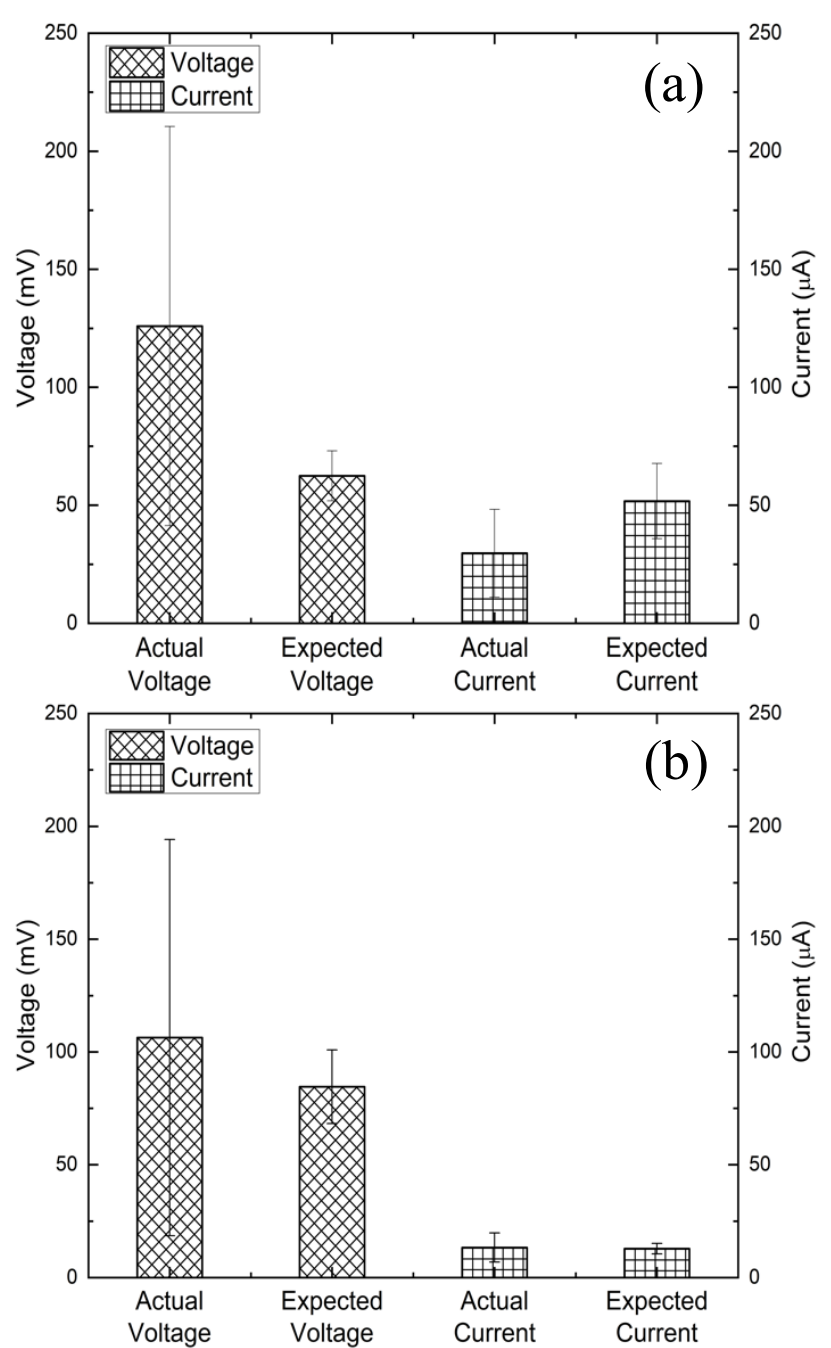

Fig 7. Voltage and current readings of PMFC stack combinations; (a) 3 sets of 3 cells in series stacked in parallel (3S-P), and (b) 3 sets of 3 cells in parallel stacked in series (3PS)

Both configurations were able to reach the expected voltage and current, even exceeding in some cases. This is important because this shows that it is possible to magnify both current and voltage in PMFCs with the proper configuration. However, connecting several series of cells in parallel (3S-P) ultimately produced the highest sustained voltage and current, and ultimately the highest power. To test if the combination stack has exceeded the performance of individual cells, a summary of power and power density for all tested systems in this study are given in Figure 8.

In general, high power and power density are sought for PMFCs. The main way to increase power is to increase the electrode surface area or stack many cells which also increases the total electrode surface area. However, a common trend observed is although power tends to increase as the electrode surface area is increased, the power density generally goes down. This happens as the incremental increase in the power due to the increased surface area is not enough to increase power density; instead, the power density quickly deteriorates as the electrode surface area increases. This is commonly seen in MFCs wherein the additional resistance of more electrode surface dilutes the power produced resulting in a lower power density(Zhang et al., 2014).

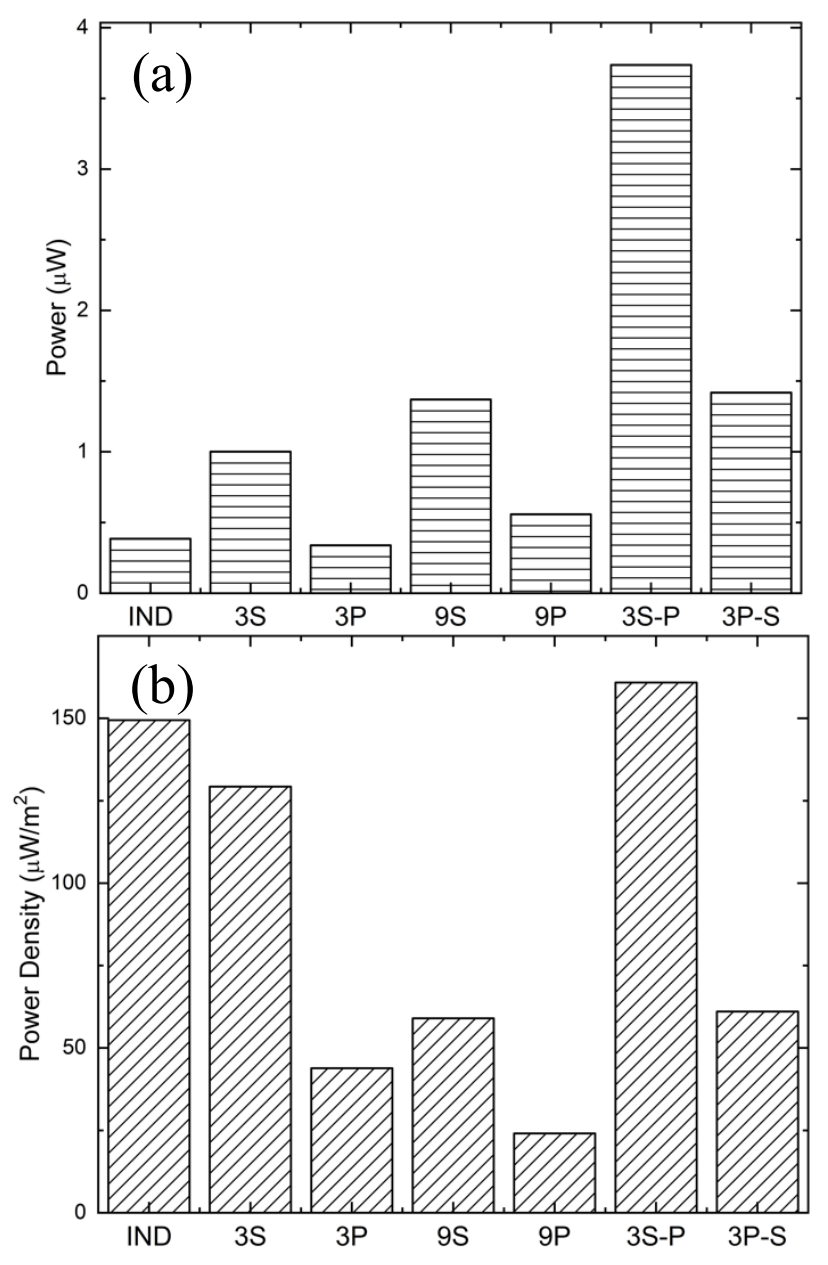

Fig 8. (a) Power and (b) power densities of all studied systems: individual (IND), 3 cells in series (3S), 3 cells in parallel (3P), 9 cells in series (9S), 9 cells in parallel (9P), 3 sets of 3 cells in series stacked in parallel (3S-P), and 3 sets of 3 cells in parallel stacked in series (3P-S)

The same was true for this study; take into consideration the succession of IND, 3S, and 9S. The number of cells increases from 1 to 3 to 9 , which also increases the anodic surface area from $25.8 \mathrm{~cm}^{2}$ to $77.4 \mathrm{~cm}^{2}$ to $232.2 \mathrm{~cm}^{2}$. In terms of power, stacking in series resulted in an increase in power $(0.39 \mu \mathrm{W}<1.00 \mu \mathrm{W}<1.37 \mu \mathrm{W}$, Figure 8a). However, since the anodic surface area increases faster than the increase in power, the trend for power density is decreasing $\left(149.45 \mu \mathrm{W} / \mathrm{m}^{2}>129.28\right.$ $\mu \mathrm{W} / \mathrm{m}^{2}>59.00 \mu \mathrm{W} / \mathrm{m}^{2}$, Figure $\left.8 \mathrm{~b}\right)$. The decrease in power density is even faster in parallel connection. This implies that neither series nor parallel connections alone are sufficient for boosting the productivity of PMFCs.

The combined stacking showed interesting results. The configuration of 3 sets of 3 cells in parallel stacked in series (3P-S) showed an increase in power compared to individual cells but a lower power density. On the other hand, the configuration of 3 sets of 3 cells in series stacked in parallel (3S-P) was able to amplify the power of an individual cell by a factor of 9.7 while maintaining a higher power density than the individual cells (160.86 $\mu \mathrm{W} / \mathrm{m}^{2}$ ). The configuration increased the power generation of PMFCs while preserving the power density of the system, which is the ultimate goal. 

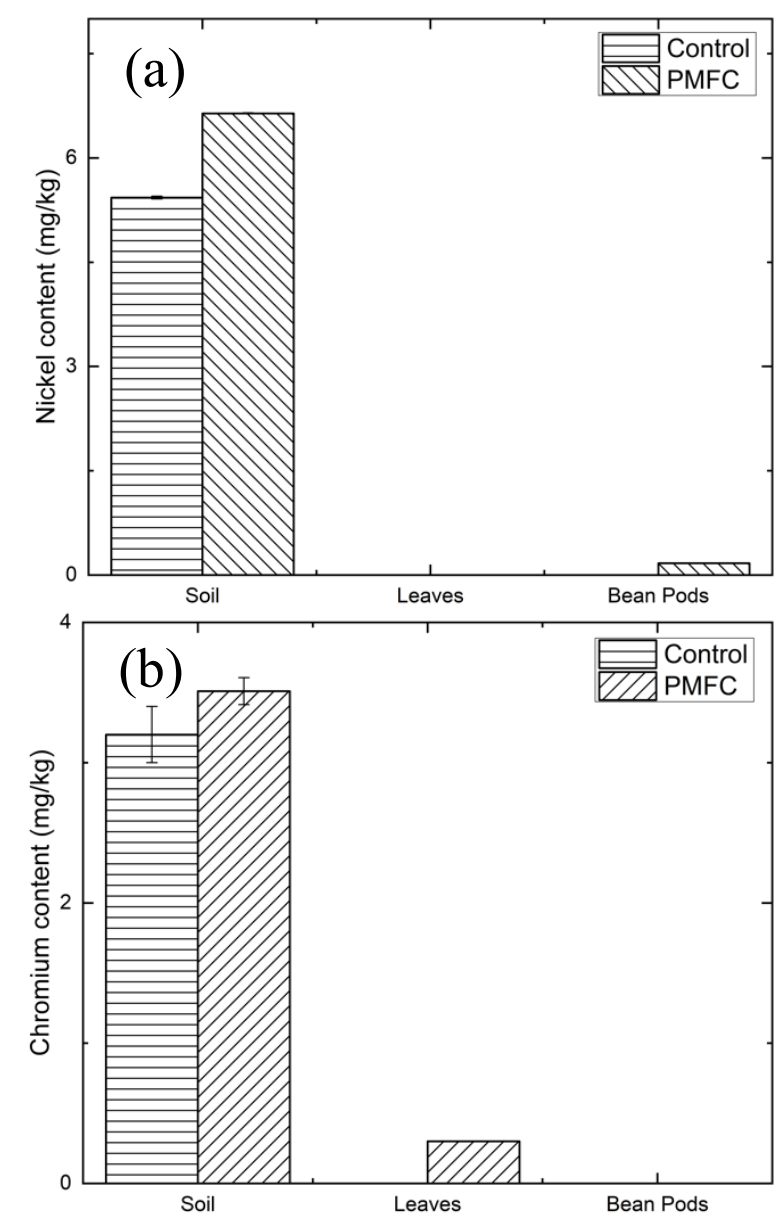

Fig 9. Concentrations of (a) nickel and (b) chromium in soil, leaves, and bean pods of PMFC compared to control (no electrodes)

\subsection{Possible Heavy Metal Contamination}

Since a catalyzing stainless-steel electrode was used as the cathode, it is of concern if it will leach heavy metals to the soil or the plant especially if PMFCs are being pushed as being able to grow food while generating electricity. The nickel and chromium content of the different parts of the PMFC are shown in Figure 9. Both nickel and chromium are naturally present in the soil albeit in varying quantities. In this case, there are existing amounts of nickel and chromium in the soil. After more than 2 months of operation, the levels of both heavy metals only increased slightly, still below the usual concentrations in soil (20 $\mathrm{mg} / \mathrm{kg}$ for Ni(Eskew, Welch, \& Cary, 1983) and $50 \mathrm{mg} / \mathrm{kg}$ for Cr (Kimbrough, Cohen, Winer, Creelman, \& Mabuni, 1999)). There is also a reason to believe that a large portion of the chromium and nickel present in the soil are in stable forms such as insoluble hydroxides because their concentrations in leaves and bean pods of the plant are very low, some even below the detection limits of ICP-OES ( $0.5 \mathrm{ppb}$ for $\mathrm{Ni}$ and $0.3 \mathrm{ppb}$ for $\mathrm{Cr}$ ). These promising results show that even with the electrical nature of PMFCs, the fruits produced by the plants are safe and are not accumulating heavy metals introduced from the electrodes. The voltage passing through the system even in stacked conditions is not enough to convert the metals into ionic species at an appreciable rate. However, care must be exercised if this will be applied to a larger system capable of generating higher voltages as it may accelerate the transfer of metals from the electrode to the soil or plant matrix. An inert electrode such as carbon-based materials could be used as cathode materials at the expense of reduced performance.

\section{Discussion}

This study is the first known attempt of a deep stacking analysis for terrestrial PMFCs. Although several studies have investigated stacking in MFCs (Ieropoulos et al., 2013)(Zhang et al., 2014)(Liu, Zhang, Liu, Wang, \& Hao, 2015)(Linares et al., 2019)(Reyes, Lat, \& Pamintuan, 2018), the difference in substrate and nutrient source made comparisons with PMFCs irrelevant. For instance, stacking reports on MFCs indicate that MFCs are stackable without much voltage reversal as long as each cell was maintained with the same nutrient media, and its consumption is at similar rates. Voltage reversal was only observed upon the depletion of nutrients wherein the degrading bacteria starved and the MFC was unable to generate enough voltage, thus affecting the stack voltage (Oh \& Logan, 2007). Theoretically, there should be no danger of voltage reversal in PMFCs if voltage reversal is caused by a lack of nutrients as the PMFC runs on rhizodeposits, which are continually supplied by the plant. However, in this study, the voltages of each cell were appreciably different from each other due to uncontrollable factors such as local microscopic differences in soil and other conditions. Those discrepancies are suspected to cause inconsistencies with predicted and actual values of both voltage and current.

A previous attempt to stack PMFCs used an aquatic system with aquatic plants(K.R.S. Pamintuan et al., 2018). The results demonstrated the ideal behavior of batteries stacked in series and parallel and no voltage reversal was observed. In an aquatic set-up, ions encounter little resistance to movement as the media is one continuous fluid matrix and thus a gradient that supports uniform diffusion is achieved. Soil, on the other hand, is highly heterogeneous and variable. The diffusivities of ions in the soil are several magnitudes lower than their diffusivities in water (Nye, 1979). The movement of ions is restricted by the water content of the soil and is hindered by air pockets, pebbles, and discontinuities within the matrix for ion movement mainly relies on diffusion though trapped solution in the pores of soil particles (Vaidyanathan, Drew, \& Nye, 1968). For this technology to be applied in a real farmland, more control over ion movement is necessary as modifying the soil just for PMFC use is impractical. One way around this problem is to decrease the distance between anode and cathode such that the ions would travel through less soil and thus increase the rate of the current generation. In a study on membrane-less MFCs, it has been observed that the voltage of the cell was highly dependent on anode-cathode spacing (Kristopher Ray S. Pamintuan et al., 2020); too close and the voltage suffers presumably due to voltage reversal induced by ions moving towards the wrong direction, too far the voltage also drops due to increased media resistance. In some studies, it was demonstrated that the anodes and cathodes can be placed near each other as long as a membrane maintains a gradient for proton diffusion (Wetser, Dieleman, Buisman, \& Strik, 
2017). This could be a superior design for terrestrial PMFCs as no soil between the anode and cathode hinders diffusion.

Stacking studies on MFCs have relied on cells on separate containers in which the working fluid has no contact from cell to cell. In this study as well, the cells are also separated by boundaries to prevent contact of substrates which will lead to short-circuiting. However, if practicality is considered for scaled-up operations, it would be very impractical to convert a planting field into discrete pots or cells to house PMFCs as they hinder normal mechanized farm operations such as tilling, soil priming, seedling transfer, etc. This poses a challenge on the design level to implement a configuration of PMFCs that is stackable to provide an appreciable amount of electricity, with means for energy storage (De La Rosa et al., 2019), and easy to deploy for ease of operations. All these efforts point to the goal of utilizing farmlands to simultaneously generate electricity and produce biomass and will be the subject of future investigations.

\section{Conclusion}

Stacking of PMFCs was successfully performed with a combination of series and parallel connections in a stack being the most efficient. The voltage and current of stacking a few cells in series or parallel mostly agreed with the theoretical values, but quickly deteriorate to low levels upon increasing the number of cells connected linearly. The configuration of 3 sets of 3 cells in series stacked in parallel was able to amplify the power of a single cell as desired while also increasing the power density. Stacking of many cells in pure series or pure parallel connections is discouraged as voltage reversal can hinder the stack from reaching its theoretical potential. Voltage reversal can also happen easily in PMFCs as several factors diversify the output of individual MFCs. Overall, the results of this study indicate the possibility of stacking PMFCs and could be used to investigate the large-scale applications of this technology.

\section{Acknowledgments}

The authors extend their gratitude to Mapua University for the support in pursuing this study.

\section{References}

Aulakh, M., Wassmann, R., Bueno, C., Kreuzwieser, J., \& Rennenberg, H. (2001). Characterization of root exudates at different growth stages of ten rice (Oryza sativa L.) cultivars. Plant Biology, 3, 139-148. https://doi.org/10.1055/s-2001-12905

Bacilio-Jiménez, M., Aguilar-Flores, S., Ventura-Zapata, E., Pérez-Campos, E., Bouquelet, S., \& Zenteno, E. (2003). Chemical characterization of root exudates from rice (Oryza sativa) and their effects on the chemotactic response of endophytic bacteria. Plant and Soil, 249(2), 271-277. https://doi.org/10.1023/A:1022888900465

Bais, H. P., Weir, T. L., Perry, L. G., Gilroy, S., \& Vivanco, J. M. (2006). the Role of Root Exudates in Rhizosphere Interactions With Plants and Other Organisms. Annual Review of Plant Biology, 57(1), 233-266. https://doi.org/10.1146/annurev.arplant.57.032905.105159
Bajracharya, S., Sharma, M., Mohanakrishna, G., Dominguez, X., Strik, D. P. B. T. B., \& Sarma, P. M. (2016). An overview on emerging bioelectrochemical systems (BESs): Technology for sustainable electricity, waste remediation , resource recovery, chemical production and beyond. Renewable https://doi.org/10.1016/j.renene.2016.03.002

Energy.

De La Rosa, E. O., Castillo, J. V., Campos, M. C., Pool, G. R. B., Nuñez, G. B., Atoche, A. C., \& Aguilar, J. O. (2019). Plant microbial fuel cells-based energy harvester system for selfpowered IoT applications. Sensors (Switzerland), 19(6), 116. https://doi.org/10.3390/s19061378

Eskew, D. L., Welch, R. M., \& Cary, E. E. (1983). Nickel: An essential micronutrient for legumes and possibly all higher plants. Science, 222(4624), 621-623. https://doi.org/10.1126/science.222.4624.621

Estrada-Arriaga, E. B., Guillen-Alonso, Y., Morales-Morales, C., García-Sánchez, L., Bahena-Bahena, E. O., GuadarramaPérez, O., \& Loyola-Morales, F. (2017). Performance of aircathode stacked microbial fuel cells systems for wastewater treatment and electricity production. Water Science and Technology, 76(3), 683-693. https://doi.org/10.2166/wst.2017.253

Greenman, J., \& Ieropoulos, I. A. (2017). Allometric scaling of microbial fuel cells and stacks: The lifeform case for scaleup. Journal of Power Sources, 356, 365-370. https://doi.org/10.1016/j.jpowsour.2017.04.033

Gurung, A., \& Oh, S. E. (2012). The improvement of power output from stacked microbial fuel cells (MFCs). Energy Sources, Part A: Recovery, Utilization and Environmental Effects, 34(17), https://doi.org/10.1080/15567036.2012.660561

Holland, B. L., Monk, N. A. M., Clayton, R. H., \& Osborne, C. P. (2019). A theoretical analysis of how plant growth is limited by carbon allocation strategies and respiration. In Silico Plants, 1(1), 1-18. https://doi.org/10.1093/insilicoplants/diz004

Hou, J., Liu, Z., \& Li, Y. (2015). Polyaniline Modified Stainless Steel Fiber Felt for High-Performance Microbial Fuel Cell Anodes. Journal of Clean Energy Technologies, 3(3), 165169. https://doi.org/10.7763/jocet.2015.v3.189

Ieropoulos, I. A., Greenman, J., \& Melhuish, C. (2013). Miniature microbial fuel cells and stacks for urine utilisation. International Journal of Hydrogen Energy, 38(1), 492-496. https://doi.org/10.1016/j.ijhydene.2012.09.062

Ishii, S., Ishii, S., Suzuki, S., Wu, A., Wu, A., Bretschger, O., ... Yamanaka, Y. (2017). Population dynamics of electrogenic microbial communities in microbial fuel cells started with three different inoculum sources. Bioelectrochemistry, 117, 74-82. https://doi.org/10.1016/j.bioelechem.2017.06.003

Khudzari, J. M., Gariepy, Y., Kurian, J., Tartakovsky, B., \& Raghavan, G. S. V. (2018). Effects of biochar anodes in rice plant microbial fuel cells on the production of bioelectricity, biomass, and methane. Biochemical Engineering Journal. https://doi.org/10.1016/j.bej.2018.10.012

Kimbrough, D. E., Cohen, Y., Winer, A. M., Creelman, L., \& Mabuni, C. (1999). A critical assessment of chromium in the environment. Critical Reviews in Environmental Science and Technology, 29(1), 1-46. https://doi.org/10.1080/10643389991259164

Kläring, H. P., Hauschild, I., \& Heißner, A. (2014). Fruit removal increases root-zone respiration in cucumber. Annals of Botany, 114(8), 1735-1745. https://doi.org/10.1093/aob/mcu192

Linares, R. V., Domínguez-Maldonado, J., Rodríguez-Leal, E., Patrón, G., Castillo-Hernández, A., Miranda, A., ... AlzateGaviria, L. (2019). Scale up of microbial fuel cell stack system for residential wastewater treatment in continuous mode operation. Water, 11(2), 1-16. https://doi.org/10.3390/w11020217

Liu, H., Zhang, B., Liu, Y., Wang, Z., \& Hao, L. (2015). Continuous bioelectricity generation with simultaneous sulfide and organics removals in an anaerobic baffled stacking 
microbial fuel cell. International Journal of Hydrogen Energy, 40(25), 8128-8136. https://doi.org/10.1016/j.ijhydene.2015.04.103

Logan, B. E., Hamelers, B., Rozendal, R., Schröder, U., Keller, J., Freguia, S., ... Rabaey, K. (2006). Microbial fuel cells: Methodology and technology. Environmental Science and Technology. https://doi.org/10.1021/es0605016

Nikhil, G. N., Krishna Chaitanya, D. N. S., Srikanth, S., Swamy, Y. V., \& Venkata Mohan, S. (2018). Applied resistance for power generation and energy distribution in microbial fuel cells with rationale for maximum power point. Chemical Engineering Journal, 335(May 2017), 267-274. https://doi.org/10.1016/j.cej.2017.10.139

Nitisoravut, R., \& Regmi, R. (2017). Plant microbial fuel cells: A promising biosystems engineering. Renewable and Sustainable Energy Reviews, 76(March), 81-89. https://doi.org/10.1016/j.rser.2017.03.064

Nye, P. H. (1979). Diffusion of ions and uncharged solutes in soild and soil clays. Advances in Agronomy, 31.

Oh, S. E., \& Logan, B. E. (2007). Voltage reversal during microbial fuel cell stack operation. Journal of Power Sources, 167(1), 11-17. https://doi.org/10.1016/j.jpowsour.2007.02.016

Pamintuan, K.R.S., Clomera, J. A. A., Garcia, K. V., Ravara, G. R., \& Salamat, E. J. G. (2018). Stacking of aquatic plantmicrobial fuel cells growing water spinach (Ipomoea aquatica) and water lettuce (Pistia stratiotes). In IOP Conference Series: Earth and Environmental Science (Vol. 191). https://doi.org/10.1088/1755-1315/191/1/012054

Pamintuan, Kristopher Ray S., Bagumba, I. H. P., \& Domingo, Z. D. G. (2020). Compartmentalization studies of a deepdesign batch Microbial Fuel Cell assembly. Journal of Physics: $\quad$ Conference Series, 1457(1). https://doi.org/10.1088/1742-6596/1457/1/012010

Pamintuan, Kristopher Ray S., \& Sanchez, K. M. (2019). Power generation in a plant-microbial fuel cell assembly with graphite and stainless steel electrodes growing Vigna Radiata. In IOP Conference Series: Materials Science and Engineering. https://doi.org/10.1088/1757-
899X/703/1/012037

Pequerul, A., Perez, C., Madero, P., Val, J., \& Monge, E. (1993). Optimization of Plant Nutrition. Optimization of Plant Nutrition, (December 2015). https://doi.org/10.1007/97894-017-2496-8

Reyes, C., Lat, D., \& Pamintuan, K. R. S. (2018). Compartmentalization, polarization, and multiple electrode optimization in PMFCs with Cynodon dactylon.

Sarojam, P. (2010). Analysis of Wastewater for Metals using ICPOES. Perkin Elmer Instruments.

Ueoka, N., Sese, N., Sue, M., Kouzuma, A., \& Watanabe, K. (2016). Sizes of Anode and Cathode Affect Electricity Generation in Rice Paddy-Field Microbial Fuel Cells. Journal of Sustainable Bioenergy Systems, 06(01), 10-15. https://doi.org/10.4236/jsbs.2016.61002

Vaidyanathan, L. V., Drew, M. C., \& Nye, P. H. (1968). The measurement and mechanism of ion diffusion in soils, 19(1).

Wetser, K., Dieleman, K., Buisman, C., \& Strik, D. (2017). Electricity from wetlands: Tubular plant microbial fuels with silicone gas-diffusion biocathodes. Applied Energy, 185 , https://doi.org/10.1016/j.apenergy.2016.10.122

Yazdi, H., Alzate-Gaviria, L., \& Ren, Z. J. (2015). Pluggable microbial fuel cell stacks for septic wastewater treatment and electricity production. Bioresource Technology, 180, 258-263. https://doi.org/10.1016/j.biortech.2014.12.100

Zhang, J., Li, J., Ye, D., Zhu, X., Liao, Q., \& Zhang, B. (2014). Tubular bamboo charcoal for anode in microbial fuel cells. Journal of Power Sources, 272, 277-282.

Zhou, Y., Tang, L., Liu, Z., Hou, J., Chen, W., Li, Y., \& Sang, L. (2017). A novel anode fabricated by three-dimensional printing for use in urine-powered microbial fuel cell. Biochemical Engineering Journal, 124, 36-43. https://doi.org/10.1016/j.bej.2017.04.012 